
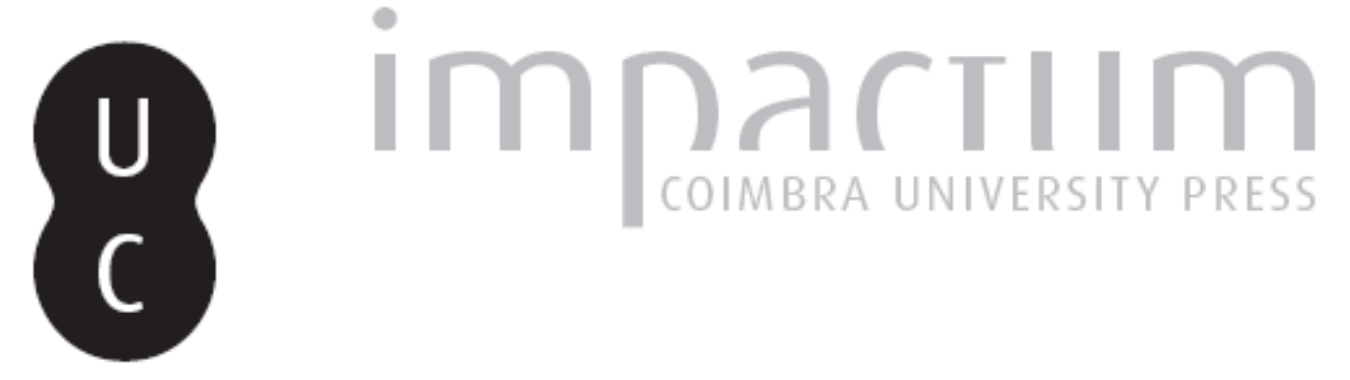

\title{
[Recensão a] M. Valverde Sánchez, H. Rodríguez Somou Nos \& C. Alcalde Martín, Plutarco. Obras morales y de costumbres (Moralia)
}

Autor(es): $\quad$ Ramón, Vicente; Vicente, Ana

Publicado por: International Plutarch Society

URL persistente:

URI:http://hdl.handle.net/10316.2/37631

DOI:

DOI:http://dx.doi.org/10.14195/0258-655X_4_7

Accessed : $\quad$ 26-Apr-2023 01:57:51

A navegação consulta e descarregamento dos títulos inseridos nas Bibliotecas Digitais UC Digitalis, UC Pombalina e UC Impactum, pressupõem a aceitação plena e sem reservas dos Termos e Condições de Uso destas Bibliotecas Digitais, disponíveis em https://digitalis.uc.pt/pt-pt/termos.

Conforme exposto nos referidos Termos e Condições de Uso, o descarregamento de títulos de acesso restrito requer uma licença válida de autorização devendo o utilizador aceder ao(s) documento(s) a partir de um endereço de IP da instituição detentora da supramencionada licença.

Ao utilizador é apenas permitido o descarregamento para uso pessoal, pelo que o emprego do(s) título(s) descarregado(s) para outro fim, designadamente comercial, carece de autorização do respetivo autor ou editor da obra.

Na medida em que todas as obras da UC Digitalis se encontram protegidas pelo Código do Direito de Autor e Direitos Conexos e demais legislação aplicável, toda a cópia, parcial ou total, deste documento, nos casos em que é legalmente admitida, deverá conter ou fazer-se acompanhar por este aviso.

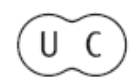


PLOUTARCHOS, n.S. Scholarly Journal of 18

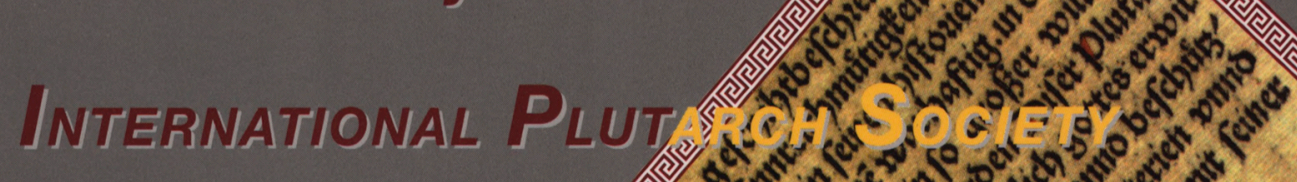

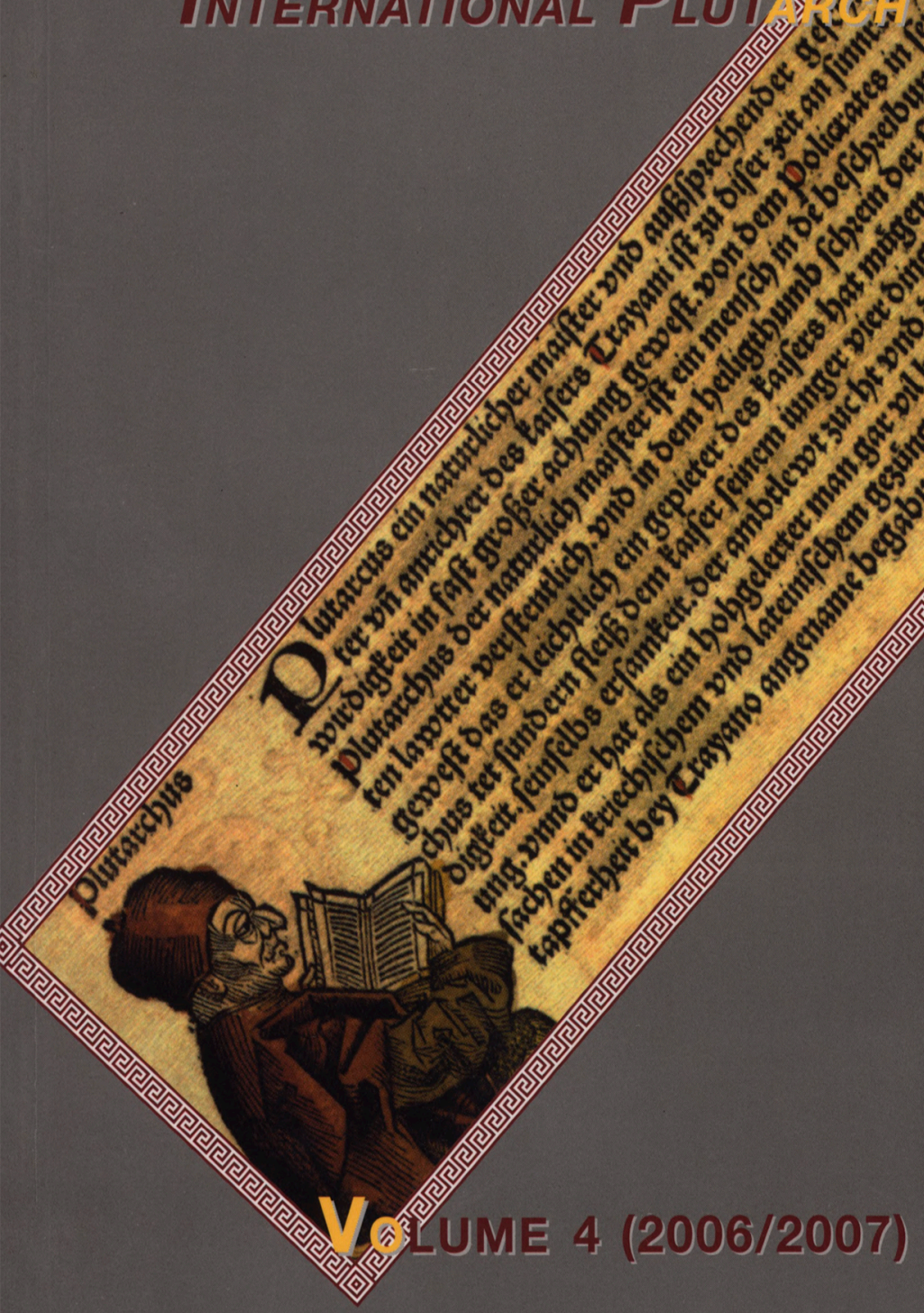

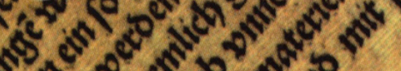

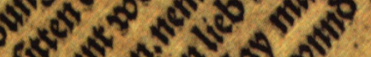

$120^{2} 0^{2} x^{2} x^{2}$

$4 \sin ^{\circ} \cos ^{\circ}$

singes

$0^{2}+0^{2} \mathrm{~s}^{\circ}$

$a^{5} x^{2}$

$s^{5}+\omega^{\circ}$

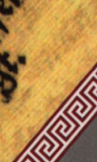

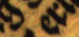

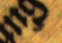




\section{BOOK REVIEWS}

M. VAlverde SÁNChez, H. RodríGuez Somou nos \& C. Alcalde Martín, Plutarco. Obras morales y de costumbres (Moralia) $X$, Madrid, Credos, 2003, 534 pp. ISBN 84-249-2381-2.

El presente volumen de la prestigiosa editorial Credos, en su Biblioteca Clásica, presenta la traducción anotada, con la pertinente introducción, de algunos opúsculos ciertamente heterogéneos en temática, género e intención. Con todo, la coherencia interna de los mismos es inmediata, ya que Mariano Valverde se ocupa de los estudios relacionados con el amor y la literatura (Erótico, Narraciones de amor, Vidas de los diez oradores, Comparación de Aristófanes $y$ Menandro), mientras que Helena Rodríguez (Sobre la necesidad de que el filósofo converse con los gobernantes, $A$ un gobernante falto de instrucción, Sobre si el anciano debe intervenir en politica) y Carlos Alcalde (Consejos políticos, Sobre la monarquía, la democracia y la oligarquía, La inconveniencia de contraer deudas) acometen los tratados de factura más propiamente política.

En rigor, Valverde presenta inicialmente una traducción novedosa del Erótico, ensayo para el que el lector hispanoparlante cuenta ya con tres traducciones de mérito a cargo, respectivamente, de los profesores García Valdés, Gilabert y Guzmán. La versión de Valverde es asimismo fidedigna y atractiva; y presenta un número significativo de variantes respecto de la edición de Flaceliére, por lo común sensatamente escogidas, aten-

PLOUTARCHOS, n.s, 4 (2006/2007) 103-130. diendo especialmente -según el criterio más acertado en la perspectiva contemporánea de la tradición textual sobre Plutarco- a las lecturas que los códices presentan, dado nuestro actual conocimiento de la koiné literaria media. Asimismo, debe reseñarse el valor intrínseco de la introducción al ensayo, considerando el enfoque que el estudioso presenta en su reivindicación (que Vaiverde concede sin ambages al queronense) del amor conyugal como punto de equilibrio en la vida de un ser humano: un amor trascendente y cualitativamente superior al homoerótico en el opúsculo de Plutarco. Como apéndice a estos relatos de índole erótica, el autor traduce, por vez primera al español, y estudia con detalle las Narraciones de Amor, un relato sensiblemente eclipsado, en la historia de la prosa plutarquea, por la simplicidad genérica del mismo y, a decir verdad, por la sombra alargada que proyecta el tratado anteriormente citado. Asimismo, Vaiverde se ocupa de los opúsculos relativos a la biografía o a la crítica literarias. Constan inicialmente las Vidas de los diez oradores, catálogo cuya redacción parece datar de los siglos III o IV d.C., lo que imposibilita su atribución al de Queronea. Se trata de una versión primera y completa al español; e igualmente constituye una traducción genuina el extracto de síntesis Comparación de Aristófanes y Menandro, obrita en la que Plutarco trae a colación los modos distinguidos de humor inherentes a los cómicos citados para, de paso, ofrecer sus propias ideas sobre el particular. En realidad -como atinadamente subraya Vaiverde en la introducción-, Plutarco se adhiere a un humor de maneras atempe- 
radas, notablemente moralizante y moralizado (al modo de Menandro), en tanto que deplora la procacidad verbal del humor burlón, escarnecedor, que representa Aristófanes.

Por su parte, Helena Rodríguez facilita las traducciones de tratados políticos que, en el inventario plutarqueo, observan una intención eminentemente pedagógica y práctica. He aquí opúsculos vertidos por primera vez a nuestra lengua; y si la temática de los mismos es parcialmente convergente, no puede indicarse lo mismo de su transmisión, estilo y notoriedad literaria. El primero de ellos \{Sobre la necesidad de que el filósofo converse con los gobernantes) presenta un texto sensiblemente deturpado en la tradición manuscrita; el segundo (A un gobernante falto de instrucción) da la impresión de no hallarse acabado; y el tercero \{Sobre si el anciano debe intervenir en política) pertenece a un período avanzado de la vida de Plutarco: precisamente aquí nuestro polígrafo despliega la versatilidad de sus recursos literarios, sin parquedad de anécdotas, citas, comparaciones de toda laya. Debe indicarse que la autora, tanto en la versión anotada como en la introducción que las precede, acierta a valorar con elegancia la singularidad de cada tratado mediante claros prólogos de presentación y traducciones notables.

Finalmente, Carlos Alcalde, quien ya cuenta con experiencia de traducción en las Vidas de Plutarco, se ajusta aquí a ensayos de naturaleza asimismo política; y priman en estos escritos las reflexiones de condición teorico-práctica. Ahí está, por ejemplo, el conocido tratado Consejos políticos, una de las más brillantes aportaciones del queronense al tema que, entre nosotros, ya estudió y tradujo F. Gaseó: aquí Plutarco refiere personalmente admoniciones de importancia a Menémaco de Sardes, un joven en quien se ha despertado la vocación política. La traducción de Alcalde es fluida y bien anotada. Tras el brevísimo --y a menudo juzgado espurio- Sobre la monarquía, la democracia y la oligarquía, constan ciertas reflexiones de cariz socioeconómico que Plutarco articula en una sinopsis de índole manifiestamente propedéutica y moral $\{$ La inconveniencia de contraer deudas): y es que Plutarco insta a que las clases acomodadas sean parsimoniosas y renuncien a la petición desmesurada de préstamos. Todo ello queda conformado, en la version de Alcalde, mediante una prosa ágil y cómodamente legible.

VICENTE RAMON \& ANA VICENTE Universidad de Zaragoza

JYT A. DuRan LÓPEZ \& R. CABAllero SÁNCHEZ, Plutarco. Obras morales $y$ de costumbres (Moralia) XL Tratados platónicos. Tratados antiestoicos, Madrid, G redos, 2004, 522 pp. ISBN 84-249-2715-X.

La "Biblioteca Clásica Credos" publicó en 2004, como número 322 de esta prestigiosa colección, el volumen XI de los Moralia de Plutarco, constituido por sus Tratados platónicos y los Tratados antiestoi$c o s$, a cargo de los profesores de la Universidad de Málaga Ma. A. Durán y R. Caballero, respectivamente.

Bajo el título de Tratados platónicos, la tradición nos ha legado dos escritos de Plutarco sobre filosofía platónica, las Cuestiones platónicas, muy breve, y el tratado Sobre la generación del alma en el "Timeo", que está seguido por el Epitome del tratado "Sobre la generación del alma en el "Timeo "”, que no es obra del autor griego, por lo que no aparece en el Catálogo de Lamprias, aunque sí en el de Máximo Planudes. Entre los tratados platónicos que menciona el primero de los catálogos figuran otros no conservados, a saber, los núms. 66, $67,68,70$ y 221 , que trataban respectivamente de la generación del Universo según Platón, de la ubicación de las Ideas, de cómo 